\title{
KNOWLEDGE, COMPLIANCE AND COMPLICATION OF CONTACT LENS USAGE AMONG MEDICAL STUDENTS IN UNIVERSITI KEBANGSAAN MALAYSIA MEDICAL CENTRE
}

\author{
Raja Lexshimi RG ${ }^{1}$, Najibah $\mathrm{AR}^{2}$, Taufiq Zahari², Lau Wei Keat ${ }^{2}$, Sim Linger ${ }^{2}$, Nur Ain Diyana Ismail ${ }^{2}$, Zaleha \\ $\mathrm{Ml}^{3}$ and Jemaima $\mathrm{CH}^{4}$ \\ ${ }^{1}$ Faculty of Nursing, Asia Metropolitan University, No. 6, Jalan Lembah, Bandar Baru Seri Alam, 81750 Masai, Johor, \\ Malaysia. \\ ${ }^{2}$ Faculty of Medicine, Universiti Kebangsaan Malaysia Medical Centre, 56000 Kuala Lumpur, Malaysia. \\ ${ }^{3}$ Department of Community Health, Faculty of Medicine, Universiti Kebangsaan Malaysia Medical Centre, 56000 Kuala \\ Lumpur, Malaysia. \\ ${ }^{4}$ Department of Opthalmology, Faculty of Medicine, Universiti Kebangsaan Malaysia Medical Centre, 56000 Kuala Lumpur, \\ Malaysia.
}

\begin{abstract}
Non-compliance to hygienic practices in contact lens wear is regarded as a significant risk factor for contact lens-related complications. Non-compliant behaviour continues to prevent efforts to improve contact lens safety despite advancements in lens materials and care solutions. The objective of this study was to identify the association between knowledge, compliance and complications of contact lens wear. A cross-sectional design was used and contact lens users among medical faculty students were identified and recruited via convenience sampling throughout October 2013 to March 2014. A total of 36 close-ended questions that focused on knowledge level, compliance to standard contact lens practice, and experience of complications were administered. A total of 188 respondents, majority of females $(89.4 \%$; $n=168)$ participated in this study. Although majority had good knowledge level $(68.1 \% ; n=128)$ on care and usage of contact lens while only a small number having moderate knowledge $(26.6 \% ; n=50)$ and poor knowledge $(5.3 \% ; n=10)$, most of them were partially compliant $(74.5 \% ; n=140)$ to the recommended contact lens practices. However, a small group was found to be fully compliant (24.4\%; $n=46)$ and the rest being non-compliant (1.1\%; $n=2)$. There was a significant association between knowledge on contact lens usage and compliance level to standard practices $(p=0.0003)$. In addition, a significant association also existed between compliance level to recommended practices and risk of complications from contact lens usage $(p=0.023)$. Findings of this study showed the positive association between knowledge of contact lens usage and compliance to recommended practices and negative association between knowledge of contact lens usage and complications experienced by contact lens users. By providing basic knowledge on contact lens care and usage via education, improvement on compliance and enhancement of safety of contact lens wear could invariably be achieved.
\end{abstract}

Keywords: Contact lens, knowledge of contact lens usage, compliance of contact lens usage, complication of contact lens usage.

\section{INTRODUCTION}

Refractive errors are top in the list when it comes to visual impairment in this modern era. Prevalence of refractive errors is tremendously high in Malaysia ${ }^{1}$, in line with the increasing prevalence globally. Myopia is the most common among the urban community compared to the less developed and suburban population. Environmental factors are cited to be the main contributing factor to this difference ${ }^{2}$. Spectacles used to be a popular mean of correcting refractive errors, a few years back until the introduction of contact lenses. Contact lenses provide a very effective way of correcting refractive errors without compromising appearance $3,4,5$. Not surprisingly, it has become increasingly popular among young generations, especially those from the urban background ${ }^{6}$.
Contact lens users need to have knowledge and skills on how to properly use and care for their contact lenses, regardless of the types of lenses and the complications that may arise from noncompliance ${ }^{7}$. Many users are successful wearers initially but each year, a large number of them become contact lens failure ${ }^{8}$. Management is often easy with no long-lasting damage but in severe cases, loss of vision may ensue. The disease burden itself, such as loss of income due to days off work and treatment costs may result in severe loss to an individual ${ }^{9}$.

Among the non-compliance behaviours noted are poor hand washing prior to lens handling, inadequate lens cleaning and disinfecting, prolonged use of contact lenses, and engaging in water activities with contact lenses on ${ }^{9,10}$. Risk of contact lens complication is thought to increase with lack of knowledge or compliance. These complications extend across a wide spectrum, from 
contact lens induced dry eyes to vision threatening microbial. It is also important to note that basic knowledge alone may not ensure correct practice of contact lens care and proper usage, even among people with background of medical knowledge.

Without a proper education focusing on the practice and care of contact lenses, complications associated with contact lens wear may increase even among consumers perceived as educated in the city setting. Proper education helps to enhance knowledge and compliance to hygienic practices of contact lens wear and eventually reduce the complications associated with it. A previous study among 121 medical students of a public university in Malaysia reported that $13.2 \%$ were not removing their contact lenses prior to sleeping at night ${ }^{11}$. Among $88.4 \%$ who were aware of complications of contact lens usage, 102 (84.3\%) were adhering strictly to proper hygiene and contact lens care; and $17(14.0 \%)$ continued wearing in spite of eye symptoms. This study also reported that 37 (30.6\%) students were not informed of complications due to contact lens usage by their contact lens prescribers. Regarding the knowledge about complications of contact lens wear, $107(88.4 \%)$ students were aware about the occurrence of corneal ulcer and/or allergic reactions; while $82(67.8 \%)$ students were aware of Pseudomonas aeruginosa and Acanthamoeba as causative organisms for corneal ulcers. This shows that even educated users such as medical students had improper practice of contact lens wear that expose them to the risk of complications. Therefore, this study was carried out to identify the association between knowledge, compliance and complications of contact lens wear among medical students in Universiti Kebangsaan Malaysia Medical Centre.

\section{METHODS}

A census was carried out to determine the number of medical students from the Faculty of Medicine, Universiti Kebangsaan Malaysia, who were using contact lens or had previous history of using contact lens. Only students doing their clinical postings in the Universiti Kebangsaan Malaysia Medical Centre were invited to participate in this study. A convenience sampling was practiced and a total of 188 respondents were recruited throughout October 2013 to March 2014. Ethics approval for this study was granted by the Universiti Kebangsaan Malaysia Research and Ethics Committee and written consent was acquired. A three-part questionnaire comprising of 36 close-ended questions on knowledge of contact lens usage, compliance to standard recommended practice of contact lens and experience of complications of contact lens wear was developed following adaptation from previous related studies. The knowledge questionnaire comprised of 12 questions adopted and adapted from a study by Tajunisah et al. (2008) ${ }^{11}$ which involved minor wording and format modification. Respondents were asked to indicate their level of agreement or disagreement in each question on a Likert-type scale running from strongly agree (5), agree (4), not sure (3), disagree (2), to strongly disagree (1). The total score was divided with the total mark and then multiplied with 100 to get the percentage. The respondent was considered having good knowledge when getting a score of $90 \%$ or more. Moderate knowledge was defined as getting a score of $70 \%$ to $89 \%$ and poor knowledge was defined as $69 \%$ or below. The compliance questionnaire was adopted and adapted from a study by Morgan (2007) ${ }^{12}$ which involved minor wording and format modification. This part consists of 14 questions. The response was assigned a score of 1 (non-compliant), 2 (partially compliant) or 3 (fully compliant). The complication questionnaire was prepared to identify any experience on complications due to contact lens usage. This part consists of 10 questions. The response was then summarized to present or absent of complication. The questionnaire was validated and its reliability tested through a pilot study and scored 0.742 on Cronbach Alpha test. The data analysis was conducted using the software SPSS for Windows version 26. Descriptive results were presented as frequency and percentages. Pearson chi-square was used to identify the association of knowledge and complication with compliance level. A p-value of less than 0.05 was considered significant.

\section{RESULTS}

Table 1 shows the total of 188 participants in which majority were female $(89.4 \%)$. In term of ethnicity, the largest proportion were Malays which contribute to $48.4 \%$, followed by Chinese $42.0 \%$, Indian $7.5 \%$ and other ethnic $2.1 \%$. For duration, majority of the respondents used the contact lens for 1 year and above (64.9\%). According to the number of hours of contact lens usage, $40.4 \%$ respondents wore it for less than 8 hours, $46.3 \%$ wore it from 8 to 12 hours and only $13.3 \%$ used it for more than 12 hours. The results also showed that majority of the respondents were having good knowledge $(68.1 \%)$ on contact lens usage. However, $74.5 \%$ were partially compliant to hygienic practices of contact lens wear. Also, majority of the respondents $(73.4 \%)$ did not suffer any complication during using the contact lens. Table 2 shows that respondents with good knowledge level showed the highest percentage of fully compliant to recommended practices of contact lens (40.6\%). This is followed by moderate knowledge level with $16.5 \%$ fully compliant and lastly poor knowledge with $0 \%$ fully compliant. Based on the result, there was a significant association between the level of 
knowledge on contact lens usage and compliance level to recommended practice of contact lens ( $p$ $=0.0003$ ). Table 3 shows that respondents without complication showed a higher percentage of fully compliant to recommended practices of contact lens $(29.0 \%)$ as compared to those with complication (12.5\%). There was a significant association between compliance level to recommended practices and risk of complications from contact lens usage $(p=0.023)$.

Table 1: Distribution of contact lens users according to gender, race, knowledge level, compliance level to recommended practice and complications of contact lens usage.

\begin{tabular}{|c|c|c|c|}
\hline Variable & & Frequency & Percent (\%) \\
\hline \multirow[t]{2}{*}{ Gender } & Female & 168 & 89.4 \\
\hline & Male & 20 & 10.6 \\
\hline \multirow[t]{4}{*}{ Race } & Malay & 91 & 48.4 \\
\hline & Chinese & 79 & 42.0 \\
\hline & Indian & 14 & 7.5 \\
\hline & Others & 4 & 2.1 \\
\hline \multirow[t]{2}{*}{ Duration } & Less than 1 year & 66 & 35.1 \\
\hline & 1 year and above & 122 & 64.9 \\
\hline \multirow[t]{3}{*}{ Number of hours } & Less than 8 hours & 76 & 40.4 \\
\hline & 8 to 12 hours & 87 & 46.3 \\
\hline & More than 12 hours & 25 & 13.3 \\
\hline \multirow[t]{3}{*}{ Knowledge } & Poor & 10 & 5.3 \\
\hline & Moderate & 50 & 26.6 \\
\hline & Good & 128 & 68.1 \\
\hline \multirow[t]{3}{*}{ Compliance } & Non-compliant & 2 & 1.1 \\
\hline & Partially compliant & 140 & 74.5 \\
\hline & Fully compliant & 46 & 24.4 \\
\hline \multirow[t]{2}{*}{ Complication } & Present & 50 & 26.6 \\
\hline & Absent & 138 & 73.4 \\
\hline
\end{tabular}

\section{DISCUSSION}

This study showed that majority of the contact lens users in UKMMC were female (89.4\%). This is in line with a previous study that there were more female users compared to male with more than one-third of the users were new to the contact lens ${ }^{12}$. The reason for this might be due to the purpose of using contact lens itself. Most of the female wore it for the cosmetic purpose, with it being able to change the colour of the user's eyes, thus enhance the user's look ${ }^{13}$. For most of the male respondents, this idea does not matter much as using spectacles are easier compared to having to put contact lens off and on. The demographics of Malaysia are represented by the multiple ethnic groups that exist in this country. This might directly reflect the sheer number of medical students according to ethnic group currently studying in UKMMC, in which the Malays are the majority, followed by Chinese, Indian and other races. This finding corresponded to a local study that showed that Malays formed the majority of the ethnic group of its research ${ }^{14}$. Most of the respondents used the contact lens for 1 year 
and above which comprised of $64.9 \%$, whereas the remaining $35.1 \%$ used it lesser than 1 year. Most of the students continue to wear contact lens for a long time, reflecting their trust and comfort of wearing the contact lens in their everyday life. This can also relate to the low percentage of students who have had complication from using the contact lens before, making them able to use it for a long period of time.

In this study, we can see that most of the respondents did not wear the contact lens for more than 12 hours. A study also showed that none of their respondents wore contact lens for more than 1 day $^{15}$. The finding could be due to the discomfort of wearing the contact lens too long in a day, where most of the respondents will remove it after coming back from the classes or finishing the ward works.
In terms of basic knowledge on contact lens wear and care, $68.1 \%$ of the students had good knowledge, $26.6 \%$ had moderate knowledge and only $5.3 \%$ had poor knowledge of contact practices ${ }^{17}$. This is because poor compliance of lens care can contribute to the bacterial contamination of the lenses that will lead to ocular infection or corneal ulceration. Eye complications have been associated with the contact lens wear, ranging from conjunctivitis and dryness symptoms to infective keratitis and corneal ulcers, which eventually cause blindness. From the results of our study, we assumed that the participants are quite wellequipped with knowledge and although not fully compliant, the compliance level is adequate in preventing the development of the contact lensinduced eye complications. Majority of the respondents had good knowledge.

Table 2: Association between knowledge level on contact lens usage and compliance level to recommended standard practice of contact lens.

\begin{tabular}{|c|c|c|c|c|c|c|}
\hline \multirow{2}{*}{$\begin{array}{l}\text { Knowledge } \\
\text { level }\end{array}$} & \multicolumn{2}{|c|}{ Compliance level } & \multirow[b]{2}{*}{ Total } & \multirow[t]{2}{*}{$x^{2}$} & \multirow[t]{2}{*}{ V } & \multirow[t]{2}{*}{ p-value } \\
\hline & $\begin{array}{c}\text { Partially } \\
\text { Compliant } \\
\text { Frequency (\%) }\end{array}$ & $\begin{array}{c}\text { Fully } \\
\text { Compliant } \\
\text { Frequency (\%) }\end{array}$ & & & & \\
\hline Poor & $8(100.0)$ & $0(0)$ & $8(100.0)$ & 15.893 & 0.292 & 0.0003 \\
\hline Moderate & $91(83.5)$ & $18(16.5)$ & $109(100.0)$ & & & \\
\hline Good & $41(59.4)$ & $28(40.6)$ & $69(100.0)$ & & & \\
\hline Total & $140(75.3)$ & $46(24.7)$ & $186(100.0)$ & & & \\
\hline
\end{tabular}

Table 3: Association between compliance level to recommended standard practice and complication of contact lens usage.

Compliance Level

$\begin{array}{lll}\mathrm{x}^{2} & \varphi & \mathrm{p} \text {-value }\end{array}$

\begin{tabular}{|c|c|c|c|c|c|c|}
\hline Complication & $\begin{array}{c}\text { Partially } \\
\text { Compliant } \\
\text { Frequency (\%) }\end{array}$ & $\begin{array}{c}\text { Fully } \\
\text { Compliant } \\
\text { Frequency (\%) }\end{array}$ & Total & & & \\
\hline Present & $42(87.5)$ & $6(12.5)$ & $48(100.0)$ & 5.199 & 0.167 & 0.023 \\
\hline Absent & 98 (71.0) & $40(29.0)$ & $138(100.0)$ & & & \\
\hline Total & $140(75.3)$ & $46(24.7)$ & $186(100.0)$ & & & \\
\hline
\end{tabular}

This could be due to the level of education of the respondents which makes them easier to understand the information that has been given to them on the usage of the contact lens. Furthermore, the respondents have background of medical knowledge in which they know what are the risks of wearing contact lens and also aware of the complications that may arise from the non- compliance of the contact lens usage. However, it surprises the researcher as there were medical students who showed poor knowledge on the contact lens usage despite the medical knowledge that they possessed.

In this study, majority (74.5\%) of the respondents were partially compliant of contact lens usage. A 
study carried out among a group of young university students in India also showed that only $34.0 \%$ of them were maintaining a satisfactory level of compliance, with the rest being partially compliant and non-compliant ${ }^{16}$. Despite the fact that majority of the respondents were having good knowledge on the contact lens usage, most of them were found to be only partially compliant. This incident can be explained by various reasons such as the cost and availability of the contact lens, the personality and habit of the contact lens users, and the time available to spend on the contact lens care.

In this study, $26.6 \%$ complained of complication while using contact lens. According to a previous study, lack of knowledge and awareness of consumers with regards to aftercare of contact lens could increase the risk of complications arising from its use $^{16}$. Our result showed that there was an association between compliance and complication of contact lens usage among the medical students. This corresponded with the finding by a study which stated that contact lens wearers are putting themselves at risk of eye infections and other related eye complications because of the poor compliance of contact lens practices ${ }^{17}$.

In addition, our study showed that there was an association between knowledge and level of compliance of contact lens usage, in which the higher the knowledge a person acquired about the proper contact lens usage, the more compliant the person will be according to the recommended practice. In this study, the non-compliant respondents $(n=2)$ were omitted during analysis as they have little effect on the overall calculation. Another study also stated that the proper education with strong emphasis on lens use and care should be implemented to reduce the risk of complications because the result showed that just the basic knowledge on contact lens cannot ensure the compliance ${ }^{16}$. However, there was a study which showed a significant portion of patients exhibited actual non-compliant despite acknowledged awareness of the risk ${ }^{18}$. The difference in the result might be due to the difference in the population. We targeted medical students as our population but their study took patients in the general community as their population. Ignorance towards the importance of proper contact lens wear and care might be less compared to the general community. As such, this would warrant appropriate steps to be taken to create awareness among the contact lens users and to train them on the right way to use and care for their lenses.

\section{LIMITATION OF STUDY}

The limitation in this study is the small sample size and the study settings. Future studies should comprise of medical students from other universities, both public and private, to get a fair comparison and a more representative finding.

\section{CONCLUSION}

We conclude that there is an association between knowledge and compliance of contact lens users among medical students in UKMMC in which the higher the knowledge, the higher the compliance. There is also an association between compliance and complication of contact lens users among medical students in UKMMC in which the higher the compliance, the lower the complication.

\section{REFERENCES}

1. Goh, PP, Yahya, A, Gopal, PP, Leon BE. Refractive error and visual impairment in Gombak district, Malaysia. American Academy of Opthalmology. 2005; 112(4): 678-685.

2. Saw, SS, Goh, PP, Cheng, A, Shankar, A, Tan, DTH, Leon BE. Ethnicity-specific prevalence rates of refractive errors vary in Asian children in neighbouring Malaysia and Singapore. $\mathrm{Br} J$ Ophthalmol. 2006.

3. B Unnikrishnan, Shakir Hussain. Pattern of use of contact lens among college students: A crosssectional study in coastal Karnataka. Indian J Ophthalmol. 2009 Nov-Dec; 57(6): 467-469.

4. Ravipati, S, Jannitha PA, Pavan, KV. Preferential and non-preferential of opting contact lens. Indian Journal of Fundamental and Applied Health Science. 2011; 1(3)

5. Philip, BM, Nathan, E, Magne, H, Motozumi, I, Deborah, J, Jason, JN et al. Demographics of international contact lens prescribing. Cont Lens Anterior Eye. 2010; 33: 27-29.

6. A Roberts, A.E. Kaye, R.A. Kaye, K. Tu and S.B. Kaye. Informed consent and devices: the case of the contact lens. Br J Ophthalmol. 2005 June; 89(6): 782-783.

7. C.W. MCMonnies. Improving patient education and attitudes toward compliance with instructions for contact lens use. Cont Lens Anterior Eye. 2011; 34: 241-248.

8. Claydon BE, Efron N, Woods C. A prospective study of non-compliance in contact lens wear. Cont Lens Anterior Eye. 1996; 19(4): 134-140.

9. Jasna Beljan, Kristina Beljan, ZdravkoBeljan. Complications caused by contact lens wearing. Coll. Antropol. 2013; 37(Suppl. 1): 179-187. 
10. Wu Y, Carnt N, Stapleton F. Contact lens user profile, attitudes and compliance to lens care. Cont Lens Anterior Eye. 2010; 33(4): 183-188.

11. Tajunisah I, Ophth M, Reddy SC, Phuah SJ. Knowledge and practice of contact lens wear and care among medical students of University of Malaya. Med J Malaysia. 2008 Aug; 63(3): 207-210.

12. Morgan, PB. (2007) Contact lens compliance and reducing the risk of keratitis. The Optician, July, 20-25.

13. Norhani Mohidin, Tee Lee Fung (2009). A survey of optometrist contact lens prescribing in Malaysia. Malaysian Journal of Health Sciences; 7(2): 59-72.

14. Ismail, L.A., Rampal, L, Abdul Rahman, $\mathrm{H}$, (2012) Non-Compliance To Lens Care Procedures In Patients With Contact Lens Related Microbial Keratitis SEGi Review ISSN 1985-5672 Vol. 5, No. 1, July 2012, 14-20.

15. Nijil Sanker, Babu Noushad (2013). Trend of Soft Contact Lens Prescribing in an Optometry Centre in India: A 6-year analysis. Journal of B.C.L.A. Volume 36 Issue 4, 196-198.

16. Madhavendra B, Hung PR (2012). Habits of Contact Lens Wearers toward Lens Care in Malaysia. Med J Malaysia Vol 67 No 3. Madhavendra B, Hung PR (2012). Habits of Contact Lens Wearers toward Lens Care in Malaysia. Med J Malaysia Vol 67 No 3.

17. Vijay Kumar, Yousef D. (2013) Importance of compliance in contact lens wear- A Study to assess the knowledge and practices among contact lens users for a healthy vision. IJCRR Vol 05 Issue 08.

18. Danielle M. Robertson, Thai H. Bui, H. Dwight Cavanagh. (2011) Patient Compliance during Contact Lens Wear: Perceptions, Awareness and Behavior. Eye Contact Lens. 